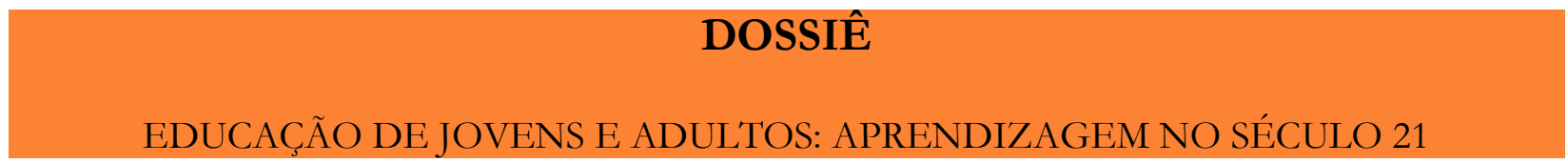
arquivos analíticos de políticas educativas

Revista acadêmica, avaliada por pares, independente, de acesso aberto, e multilíngüe

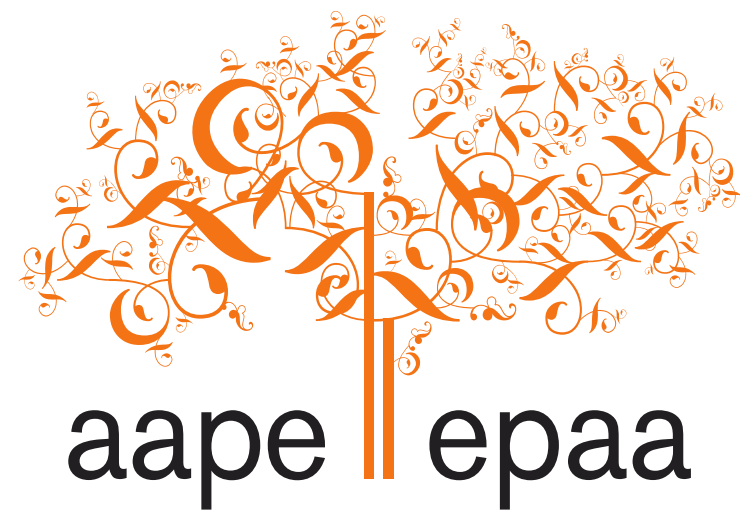

Arizona State University

Volume 21 Número $76 \quad$ Setembro $23^{\text {rd }}, 2013$

ISSN 1068-2341

\title{
Trajetórias e vivências escolares de mulheres em situação de privação de liberdade
}

\author{
Maria Celeste Reis Fernandes Souza \\ Secretaria Municipal de Educação de Governador Valadares \\ Maria Gabriela Parenti Bicalho \\ Universidade Vale do Rio Doce - UNIVALE \\ Eunice Maria Nazareth Nonato \\ Centro Universitário Metodista Izabela Hendrix \\ Brasil
}

Citação: Reis Fernandes Souza, M.C., Parenti Bicalho, M. G., e Nonato, E. M. N, (2013). Trajetórias e Vivências Escolares de Mulheres em Situação de Privação de Liberdade. Arquivos Analíticos de Políticas Educativas, 21(76). Recuperado [data] http://epaa.asu.edu/ojs/article/view/1335 Dossiê Educação de Jovens e Adultos; Editoras convidadas: Sandra Regina Sales \& Jane Paiva

Trajetórias e vivências escolares de mulheres em situação de privação de liberdade Resumo: $\mathrm{O}$ artigo se insere na discussão sobre a educação de mulheres em situação de privação de liberdade, tema que tem merecido atenção de estudiosos e estudiosas do campo da Educação de Pessoas Jovens e Adultas - EJA. Os dados apresentados foram coletados no contexto de uma pesquisa que analisou a constituição das experiências educativas escolarizadas de mulheres, jovens e adultas, em situação de aprisionamento, no Estado de Minas Gerais. Referem-se especificamente aos relatos produzidos em entrevistas realizadas com 05 (cinco) mulheres que frequentam a escola em uma dessas instituições, e com 01(uma) pedagoga responsável pelo acompanhamento de 
experiências educativas escolarizadas em instituições prisionais do estado. A análise das narrativas produzidas pelas entrevistadas toma como referência a teoria da relação com o saber proposta por Bernard Charlot, de maneira específica os conceitos de mobilização, sentido e atividade. Os relatos das experiências escolares mostram duas situações diferentes no que diz respeito às condições de acesso e permanência na educação básica: trajetórias marcadas por dificuldades e interrompidas precocemente e outras mais regulares e duradouras. A prisão constitui, portanto, para algumas mulheres, a possibilidade de retomar o ensino fundamental, e, para outras, a impossibilidade de prosseguir o ensino médio. Apesar dessas diferenças, é possível identificar nos relatos aspectos comuns, no que diz respeito aos sentidos da educação escolar, à mobilização em relação ao aprender e à realização das atividades na escola da prisão. Tais aspectos são apresentados e discutidos como elementos de compreensão da complexa realidade da educação de mulheres jovens e adultas no sistema prisional.

Palavras-chave: Relação com o saber; Gênero; Sistema prisional; EJA.

Trajectories and experiences of schooling of women in situations of imprisonment Abstract: This article is part of the discussion on the Education of women in situations of deprivation of liberty, a topic that has received attention from scholars in the field of Young and Adult Education. The data presented were collected in the context of a study that analyzed how the educational experiences of educated women are shaped in situations of imprisonment in the State of Minas Gerais. It refers specifically to reports produced on interviews with 5 women who attend school in one of these institutions, and 1 educator who is responsible for monitoring educational experiences in state prisons. The analysis of the interviews uses the theory of relationship with knowledge proposed by Bernard Charlot, especially the concepts of mobilization, sense and activity. The reports of school experiences show two different situations with regard to the conditions of access to basic education and the retention of students to it: paths marked by difficulties and halted prematurely, and other more regular and long lasting trajectories. Therefore prison is for some women the possibility of resuming elementary school, and for others, the inability to get to secondary school. Despite these differences, it is possible to identify common aspects in the stories that range from the perspectives on school education to the mobilization in relation to learning and achievement in school activities in prison. These aspects are presented and discussed as essentially important elements in order to understand the complex reality of the education of young and adult females in the prison system.

Keywords: Relationship with knowledge; Gender; Prison system; Youth and Adult Education.

\section{Trayectorias y vivencias escolares de mujeres en situación de privación de libertad}

Resumen: El artículo discute la educación de las mujeres en situaciones de privación de libertad, un tema que ha recibido mucha atención en el campo de la Educación de Jóvenes y Adultos - EJA. Los datos presentados fueron recogidos en el contexto de un estudio que analizó la constitución de las experiencias educativas de las mujeres en situaciones de privación de libertad en el Estado de Minas Gerais. Se refieren a los informes producidos en entrevistas con 05 de las mujeres, alumnas de EJA en una de estas instituciones, y 01 pedagoga responsable por acompañar las experiencias educativas en estas instituciones. El análisis de las narrativas toma como referencia la teoría de la relación con el conocimiento de Bernard Charlot específicamente los conceptos de movilización, sentido y actividad. Los informes de las experiencias escolares muestran dos situaciones diferentes con respecto a las condiciones de acceso y permanencia en la educación básica: caminos marcados por las dificultades y por la interrupción temprana y otros marcados por experiencias más regulares y de larga duración. La prisión para algunas mujeres, significa la posibilidad de volver a la escuela, y para otras, la imposibilidad de continuación. A pesar de estas diferencias, es posible identificar elementos 
comunes en las historias con respecto a los sentidos de la educación escolar, la movilización en relación con el aprendizaje y las actividades escolares. Estos aspectos se presentan y se discuten como elementos para la comprensión de la compleja realidad de la educación de las mujeres en el sistema penitenciario.

Palabras-clave: Relación con el conocimiento; Género; Sistema penitenciario; Educación de Jóvenes y Adultos.

\section{Introdução}

Neste artigo, buscamos contribuir com a discussão sobre a educação de mulheres em situação de privação de liberdade ${ }^{1}$. Segundo dados divulgados pelo Ministério da Justiça (Brasil, 2008) constata-se no Brasil, nos últimos anos, uma tendência ao aumento significativo de mulheres nessa situação. Com relação à escolarização dessas mulheres o documento "Educação nas Prisões Brasileiras", elaborado pela Relatoria Nacional para o Direito Humano à Educação, apresenta um quadro preocupante: "quase $80 \%$ das mulheres não têm o ensino fundamental completo"(Carreira, 2009, p.28).

$\mathrm{Na}$ última década, temos acompanhado, no Brasil, as preocupações com o reconhecimento do direito à educação de pessoas jovens e adultas em situação de aprisionamento, por parte da sociedade civil, dos movimentos organizados em prol dos direitos humanos, de educadores, do sistema judiciário, de governos, de pesquisadores/as, que culminam, em 2010, com a homologação e publicação das Diretrizes Curriculares Nacionais para a Educação Prisional ${ }^{2}$ (Brasil, MEC, 2010) momento em que a política nacional assume o direcionamento da educação em um espaço, até então, considerado como sendo próprio das questões judiciais.

No documento referência "A educação para jovens e adultos em situação de restrição e privação de liberdade no Brasil: questões, avanços e perspectivas", apresentado em abril de 2012, no Seminário Educação nas Prisões, realizado em Brasília, Sauer e Julião (2012) destacam como principais conquistas para a educação no contexto prisional:

a aprovação das Diretrizes Nacionais para a oferta de educação nos estabelecimentos penais pelo Conselho Nacional de Política Criminal e Penitenciária (Resolução no 3 de 11/03/2009 do (NPCP) e das Diretrizes Nacionais para a oferta de educação para jovens e adultos em situação de privação de liberdade nos estabelecimentos penais pelo Conselho Nacional de Educação (Parecer CNE/CEB nº 4/2010 e Resolução CNE/CEB no 2 de 2 19/05/2010); e, por conseguinte, a alteração na Lei de Execução Penal que permite às pessoas presas diminuírem a sua pena com base nas horas de estudo (Sauer e Julião, 2012, p 3).

Por sua vez, a preocupação com a educação de mulheres, as correlações de gênero e a equiparação histórica das desigualdades de gênero encontram-se na pauta de debates diversos no cenário nacional e internacional. De modo específico, no campo da EJA, essa tem sido uma questão recorrente, como pode ser constatado nos documentos da V e IV Conferências Internacionais sobre

\footnotetext{
${ }^{1}$ No campo da EJA, utiliza-se a denominação "pessoas em situação de privação de liberdade" para referir-se a presos/as, detentos/as ou apenados/as. Pretende-se com essa denominação evitar a utilização de palavras que estigmatizam os sujeitos e, ao mesmo tempo, considerar as singularidades e especificidades características do público da EJA (Ireland, 2009).

${ }^{2}$ Embora o reconhecimento ao direito da pessoa jovem e adulta privada das condições de acesso à educação se apresente com o advento da Constituição Federal Brasileira de 1988, consideramos relevante observar que desde 1984, portanto, quatro anos antes, a Lei de Execução Penal (LEP) já contemplava a educação como possibilidade para as pessoas em situação de privação de liberdade.
} 
EJA - CONFINTEA ${ }^{3}$. Esses debates têm provocado questionamentos sobre processos, práticas educativas e correlações de gênero e contribuído para o avanço da situação educacional de mulheres, em relação ao reconhecimento do direito ao acesso e permanência na escola.

As oportunidades educativas ofertadas às mulheres nas unidades prisionais do país têm sido discutidas e, em diversos aspectos, questionadas, seja pela extensão da oferta, seja pela efetividade dessa oferta na continuidade dos estudos dessas mulheres (Graciano, 2005; Graciano e Schilling, 2008; Nonato, 2010 e 2011; Souza et. al 2012; Souza, Caetano e Rosa, 2012; Yamamoto et al2010). Colares e Chies (2010, p.408) apontam como duas questões atuais das políticas prisionais o crescimento da taxa de encarceramento feminino e "... o improviso institucional no enfrentamento e no atendimento dessa recente demanda."

Nos trabalhos sobre o tema, discute-se o papel do estado e da sociedade civil na garantia do direito à educação para as mulheres em situação de privação de liberdade, e ficam evidentes a multiplicidade e a complexidade dos fatores envolvidos nos processos educativos desenvolvidos nas prisões.

Nosso propósito neste artigo é ampliar as discussões no campo da EJA sobre a oferta da educação em instituições de privação de liberdade. Ao trazermos à cena as preocupações com a educação de mulheres, pretendemos contribuir para o debate sobre gênero e EJA,lançando olhares sobre a prática educativa no contexto de privação de liberdade,no qual as mulheres estão cada vez mais presentes.

\section{Percursos Teóricos e Metodológicos da Pesquisa}

Os dados apresentados foram coletados no contexto de uma pesquisa que analisou a constituição das experiências educativas escolarizadas de mulheres, jovens e adultas, em situação de aprisionamento, no Estado de Minas Gerais ${ }^{4}$. O campo investigado abrange 03 instituições prisionais exclusivamente femininas desse estado e a metodologia empregada incluiu: um questionário que traçou o perfil social de 137 mulheres em cumprimento de pena nessas instituições, análise dos projetos pedagógicos de duas instituições que ofereciam a experiência escolarizada e entrevistas abertas com 10 alunas de escolas localizadas nas prisões e 02 pedagogas responsáveis pelo acompanhamento da experiência educativa escolarizada oferecida em 02 instituições.

No presente trabalho, aprofundamos a análise das entrevistas realizadas com 05 mulheres que frequentam aulas de EJA em uma das instituições prisionais pesquisadas e que funciona no sistema APAC (Associação de Proteção e Assistência aos Condenados) ${ }^{5}$. A escolha das mulheres entrevistadas contemplou diferentes faixas etárias e diferentes níveis de escolaridade, sem pretender gerar uma amostra representativa.

3V CONFINTEA - Conferência Internacional sobre Educação de Adultos. Conferência realizada em Hamburgo, Alemanha, em julho de 1997. VI CONFINTEA - Conferência Internacional sobre Educação de Adultos. Conferência realizada em Belém, Brasil, em dezembro de 2009.

${ }^{4}$ Pesquisa iniciada em março de 2011 com apoio do Conselho Nacional de Desenvolvimento Científico e Tecnológico - CNPq.

5"A APAC - Associação de Proteção e Assistência aos Condenados é uma entidade civil de Direito Privado, com personalidade jurídica própria, dedicada à recuperação e reintegração social de condenados a penas privativas. O trabalho da Apac dispõe de um método de valorização humana, vinculada à evangelização, para oferecer ao condenado condições de se recuperar. Busca, também, em uma perspectiva mais ampla, a proteção da sociedade, a promoção da justiça e o socorro às vítimas” (TJMG, 2009, p. 17). 
$\mathrm{Na}$ análise das entrevistas, direcionamos nossa atenção aos relatos que elas produziram, à maneira como narraram suas trajetórias escolares, como descreveram a escola na prisão, aos casos que contaram, às situações que escolheram para nos contar nas entrevistas. Entendemos que são relatos produzidos durante as entrevistas e que elas disseram aquilo que julgaram ser pertinente naquela situação - o cuidado com o que se diz é maior dentro de uma instituição prisional - como pudemos comprovar em nossa inserção como pesquisadoras nesse campo. Ainda assim, entendemos que o que foi dito nas entrevistas nos possibilita, por nossa vez, dizer algo acerca da educação de mulheres em situação de privação de liberdade, que possa ajudar a compreender a complexidade dessa realidade.

Para ampliar a compreensão sobre o contexto da escola na qual essas mulheres encontram-se inseridas, utilizamos dados da entrevista realizada com a pedagoga que acompanha o processo educativo na instituição prisional.

Ao analisarmos trajetórias escolares de mulheres, não podemos ignorar o proposto por Joan Scott sobre a necessidade de tomar o gênero como categoria de análise (Scott, 1990). Assim, os estudos que nos levam a compreender o gênero como produzido nas e produzindo as relações sociais (Louro, 1997) e como "construção social da diferença entre os sexos" (Perrot, 2005, p.467) balizaram nosso modo de olhar na análise das entrevistas.

Tal opção engendra um exercício teórico de evitar o que Valerie Walkerdine (2003) chama de "armadilha" " em pesquisas sobre mulheres. Embora a autora tenha como centro das suas investigações as relações de gênero e matemática, acreditamos que suas reflexões são pertinentes para nossa análise. Isso porque, de certo modo, ao narrarem suas trajetórias as mulheres entrevistadas apresentaram relações com o conhecimento cuja compreensão não pode se restringir a uma análise cognitiva que, ao reafirmar diferenças entre mulheres e homens, estabelece desigualdades de gênero.

Encontramos na teoria da relação com o saber proposta por Bernard Charlot (1999, 2000, 2001, 2005) uma abordagem teórica por meio da qual pudemos dialogar com os estudos de gênero na análise dos dados da pesquisa. Desse ponto de vista, não é possível pensar nem o saber nem o sujeito de saber fora da relação do sujeito com o saber, ou seja, o saber só pode ser pensado como relação. Essa relação é estabelecida por um sujeito em um mundo que lhe é anterior, construído nas relações de outros sujeitos. Considerando a perspectiva da "sociologia do sujeito" proposta por Bernard Charlot (2000), a análise das entrevistas buscou considerar tanto os determinantes sociais das experiências educacionais vivenciadas pelas mulheres presas (em sua trajetória pregressa e também na escola da instituição prisional) quanto o caráter fundamentalmente subjetivo dessas trajetórias e vivências. Destacamos, na interpretação dos dados da pesquisa, três elementos que Bernard Charlot (2000) apresenta como constitutivos da "relação com o saber": sentido, mobilização e atividade.

6 A autora utiliza a palavra "trap" para mostrar como, ao analisarmos correlações de Gênero e Matemática, devemos cuidar para não cairmos nas armadilhas que produzem diferenciações e desigualdades. As traduções dos textos em inglês são da nossa autoria.

${ }^{7}$ A respeito do conceito de Gênero, afinidades políticas e tensões teórico-metodológicas, sugerimos cf. Louro (2007). 


\section{Trajetórias e Vivências Escolares}

Foram cinco as mulheres que forneceram os relatos de suas experiências educativas: Cândida, Ângela, Cecília, Márcia e Vilma ${ }^{8}$. A análise dos relatos das experiências escolares mostra duas situações diferentes no que diz respeito às condições de acesso e permanência na educação básica: trajetórias marcadas por dificuldades e interrompidas precocemente e outras mais regulares e duradouras. A prisão constitui, portanto, para algumas mulheres, a possibilidade de retomar o ensino fundamental, e, para outras, a impossibilidade de prosseguir o ensino médio. Apesar dessas diferenças, é possível identificar nos relatos aspectos comuns, no que diz respeito aos sentidos da educação escolar, à mobilização em relação ao aprender e à realização das atividades na escola da prisão. Tomando como referência essas duas situações agrupamos as mulheres entrevistadas em dois grupos apresentados a seguir.

No primeiro grupo, encontramos Cândida, Márcia e Vilma. Elas tiveram sua trajetória escolar interrompida pelas dificuldades econômicas, pela discriminação, pela gravidez precoce, situações que marcam a vida de muitas mulheres, alunas da EJA, como mostram narrativas de diferentes mulheres da EJA em pesquisas sobre gênero e EJA (NOGUEIRA, 2003; SOUZA, 2008, SOUZA e FONSECA 2008, 2010). Revela-se nessas trajetórias a ausência do direito ao acesso e à continuidade da vivência escolar. Para elas, paradoxalmente, a prisão foi a oportunidade de retomar os estudos, oportunidade que avaliam que não teriam em liberdade. Revelam a preocupação e a dedicação na orientação de seus filhos e suas filhas no sentido de não abandonarem a escola, mostrando como as preocupações com o cuidado marcam a vida dessas mulheres, assim como, de muitas outras mulheres, alunas da EJA, como os estudos já citados demonstram.

Cândida tem 30 anos, estudou até a quarta série do Ensino Fundamental. Iniciou seu percurso escolar aos 7 anos, e parou na quinta série: "entrei na escola eu tava com sete anos, eu fiz a $1^{\mathrm{a}}$, a $2^{\mathrm{a}}$, a $3^{\mathrm{a}}$, a $4^{\mathrm{a}}$. Aí passei pra $5^{\mathrm{a}}$ e saí da escola, parei de estudar, comecei trabalhar". Tentou retomar os estudos no período noturno, mas não prosseguiu: "comecei ver que não tava dando pra eu estudar a noite porque tava muito perigoso o bairro, eu parei de estudar". A situação de privação de liberdade trouxe a ela a oportunidade de retomar os estudos: “....só que graças a Deus aqui voltei a estudar, pretendo voltar a estudar quando eu sair daqui."

Segundo ela, o abandono da escola na quinta série aconteceu contra a vontade de sua mãe: "era pra eu renovar minha matrícula, aí eu falei: - mãe eu não vou estudar mais. Aí minha mãe[disse]: - não minha filha estuda". Agora, de volta à escola, na prisão, ela vive situação parecida com sua própria filha: "e a minha filha agora tem 14 anos e também não quer ir pra escola. Aí eu mandei uma carta pra ela falando o mesmo que a minha mãe falou". Ao ser perguntada se não estivesse presa estaria estudando, ela respondeu que achava que não, "porque eu não tinha incentivo nenhum. Entendeu? Eu ia olhar logo assim não eu não vou estudar! Eu já tava parada! Eu ia continuar parada."

A oportunidade de retomar os estudos na prisão aparece também em relação à regularização da documentação escolar. Cândida, que não possuía registros sobre sua passagem na escola, é submetida a um processo de avaliação pela pedagoga e incluída na turma de EJA. Ela relata que após sair da prisão poderá se matricular em uma escola: "veio até uma mulher aqui ontem e falou que eu passei na prova e que não tinha nenhum documento meu agora já tem. Então eu posso sair e já começar estudar!”

Vilma tem 40 anos, estudou até a quinta série do Ensino Fundamental, o que fez dos 7 aos 10 ou 12 anos de idade. Relata uma infância com muitas privações e problemas, entre os quais o

${ }^{8}$ Os nomes são fictícios para preservar a identidade das pessoas envolvidas. 
alcoolismo da mãe, o que a impedia de acompanhar e estimular a vida escolar de Vilma e suas três irmãs. Ao falar sobre os motivos que a levaram a deixar a escola, Vilma apresenta dois aspectos: a discriminação sofrida por ser negra e a necessidade de ajudar a mãe a criar as irmãs mais novas. Ela relata: "eu não tive muito carinho de mãe, né? Pra continuar os meus estudos, né? E foi muito sofrimento na minha infância, então não tive .... e na escola sofri humilhação entendeu? Eu desisti da escola, fui trabalhar, saí da escola."

$\mathrm{Na}$ tentativa de oferecer aos filhos e às filhas uma situação diferente, ela buscou valorizar e estimular a escolarização deles e delas, o que relaciona inclusive com o crime cometido.

"Essa cadeia toda que eu tô pagando foi pra mim poder manter os estudo deles coisa que eu não tive oportunidade eu dei pra eles estudar, coisa que a minha mãe nunca teve condições de me dar eu dei pra eles, pra eles estudar, sempre foi muito bem vestido pra escola, muito bem arrumado pra não ter mesmo de sofrer o que eu sofri né? E então foi onde que eles estudaram né? Até animava eles pra ir pra escola. Meu menino abandonou a escola, largou, mas eu saindo agora vou ver se eu converso com ele, ele tem dezessete anos."

$\mathrm{Na}$ prisão, ela retomou os estudos. "Eu só fiz até a quinta série, eu só fiz a quinta, agora eu tô fazendo a quinta e a sexta, no ano que vem eu vou pra sétima, se Deus quiser eu vou terminar." Márcia tem 53anos e frequentou a escola até o segundo ano do Ensino Fundamental. Fala sobre o início de sua vida escolar na zona rural, da longa caminhada que fazia, junto com os irmãos, para chegar a uma escola "tão humilde, era de tábua, de tábua e cheia de buraco a escola".

"Na época meu pai, quando nós começamos a estudar, ele fazia aqueles lápis de bambuzinho, bambuzinho de rosa. Até que a gente aprendesse a escrever né? Aí então a gente começou estudar, andava, andava, andava um tempão pra gente chegar na escolinha e a gente ia brincando, e as vezes nós era tão relaxado que nós ficava brincando e quando assustava nós voltava, não ia na escola não e a minha mãe chegava e dava um coro em nós, e chegava lá e falava com a professora pra por nós de castigo".

Era difícil aprender a ler: aí eu fiquei num tal de $\mathrm{ABC}$, que era $\mathrm{ABC}$ antigamente né? $\mathrm{ABCD}$ e tal e eu era, nosso Deus, cabeça dura, não queria aprender de jeito nenhum. Ela estudou nessa escolada zona rural até o segundo ano, e então parou de estudar. Mudou-se para a cidade aos 10 anos, a mãe matriculou-a na escola novamente, mas ela "não quis mais estudar". Casou cedo e teve três filhas. Separou-se do marido e, para sustentar as filhas, começou a trabalhar. Embora participe da turma de EJA na APAC, $2^{a}$ etapa do Ensino Fundamental, e tenha estudado até o $2^{\circ}$ ano do Ensino Fundamental, é acompanhada pela professora de Português e pelo professor de Matemática, que organizam para ela atividades diferentes das outras alunas e que envolvem leitura, escrita e operações matemáticas.

Cândida, Márcia e Vilma possuem em comum, portanto, a trajetória escolar marcada por dificuldades e interrompida precocemente. Além disso, as três encontraram na prisão a possibilidade de voltar a estudar. Outras duas entrevistadas produziram relatos que apresentam situações diferentes das anteriores. Ângela e Cecília avançaram bem mais na escolaridade, com trajetórias marcadas pelo sucesso escolar, apesar de dificuldades enfrentadas. Por isso, não encontram na condição de privação de liberdade possibilidade de continuidade dos estudos. Elas apresentam a demanda da realização do ensino médio e do ensino superior.

Cecília tem 24 anos. Quando foi presa, cursava o segundo ano do ensino médio, no curso Normal de uma escola tradicional da cidade. Relata uma trajetória regular, de sucesso escolar, que foi interrompida pela prisão. Enquanto estudava, sonhava em fazer curso superior de Administração. À época da entrevista, desejava a oportunidade de cursar o segundo e o terceiro anos do Ensino Médio enquanto cumpria sua pena, pois ainda faltava um ano para acabar de cumpri-la. "Aí eu tô querendo fazer dois anos em um, tô querendo estudar na escola aqui perto". Perguntada se teria essa 
oportunidade, ela afirma que "se a gente correr atrás, a gente consegue. Conversando com o Juiz que o juiz vem aqui uma vez no mês. Aí conversando com ele, ele abre a oportunidade".

Ângela tem 21 anos, começou a estudar aos 7 anos de idade e parou aos quatorze anos, na oitava série, porque engravidou e "não tinha mais condições de ir pra escola. Não tinha com quem deixar o meu filho e eu tive que assumir toda uma responsabilidade de mãe, mas o meu sonho era voltar a estudar. Meu sonho ainda é acabar de estudar e fazer uma faculdade". Ela retomou os estudos na APAC para concluir a oitava série, sete anos depois de ter abandonado a escola. Entretanto, apesar de importante, a oferta de estudos na unidade prisional não será suficiente para que Ângela prossiga estudando após a conclusão do Ensino Fundamental, considerando-se que não há a oferta de Ensino Médio.

Cecília e Ângela demonstram a construção de uma visão positiva de si mesmas enquanto alunas.Afirmam que tinham facilidade nas matérias, boas notas e que gostavam da escola e das atividades escolares. Cecília, mesmo não se beneficiando da certificação oferecida pela escola, frequentava as aulas, para "lembrar" do que tinha aprendido.

O reconhecimento das diferenças entre as trajetórias escolares das mulheres presas (as quais, neste artigo, nos levaram a dois grupos com percursos distintos) é importante e coloca para a Educação de Pessoas Jovens e Adultas questões e demandas diferenciadas. Entretanto, essas diferentes trajetórias encontram-se com uma condição comum: a oferta de educação escolarizada por uma instituição prisional, na qual se encontram: a APAC.

Sobre essa instituição, a publicação do Tribunal de Justiça do Estado de Minas Gerais TJMG "Projeto novos rumos da execução penal"afirma:

A principal diferença entre a Apac e o Sistema Carcerário Comum é que na Apac os próprios presos (chamados de recuperandos pelo método) são co-responsáveis pela sua recuperação e têm assistência espiritual, médica, psicológica e jurídica prestadas pela comunidade. A segurança e a disciplina do presídio são feitas com a colaboração dos recuperandos, tendo como suporte funcionários, voluntários e diretores das entidades, sem a presença de policiais e agentes penitenciários. (TJMG, 2009, p.17)

Para entender a escola neste espaço prisional, recorremos às informações da entrevista com a pedagoga sobre o seu funcionamento.

Nesta APAC, o município se responsabiliza pela oferta de uma turma de EJA da $2^{a}$ etapa do Ensino Fundamental iniciada em 2009. Esta turma se constitui em um anexo de uma das escolas municipais da rede e atende separadamente às mulheres, conforme o tipo de regime: regime fechado e regime semiaberto ${ }^{9}$. Durante as entrevistas, como já relatamos, as mulheres que já concluíram o Ensino Fundamental, algumas na própria instituição prisional, solicitam a oferta do Ensino Médio na instituição, ou a possibilidade de matrícula em escolas estaduais. Entretanto, prevalecem dificuldades burocráticas de garantia desse acesso para conclusão dos estudos, tanto pelos limites da organização da institucional prisional, ou pelos órgãos competentes responsáveis pela oferta do Ensino Médio.

$\mathrm{O}$ acesso das mulheres à escola se faz desde o momento em que ingressam na APAC. Ao ser identificado pela funcionária da instituição que a recuperanda não completou o Ensino Fundamental ela é encaminhada à escola. A regularização da vida escolar da aluna (conferência de histórico escolar

\footnotetext{
${ }^{9}$ De acordo com a Lei de Execução Penal - LEP o tipo de regime é estabelecido conforme o determinado judicialmente para cumprimento da pena privativa de liberdade. De acordo com o artigo 112 da LEP a pena privativa de liberdade será executada em forma progressiva com a transferência para regime menos rigoroso (regime semiaberto e aberto), a ser determinada pelo juiz, quando o/a preso/a tiver cumprido ao menos um sexto da pena no regime anterior e ostentar bom comportamento carcerário, comprovado pelo diretor do estabelecimento.
} 
ou classificação ${ }^{10}$ ) é feita pela pedagoga da escola municipal que acompanha a turma de EJA na instituição prisional. Pelos princípios que regem o sistema APAC, a educação, assim como o trabalho, é obrigatória no processo de ressocialização das recuperandas.

As aulas acontecem de segunda a sexta-feira e tem duração de duas horas e meia atendendo ao denominado pela escola $1^{\circ}$ segmento ( $5^{\mathrm{a}}$ e $6^{\mathrm{a}}$ séries $)$ e o $2^{\mathrm{o}}$ segmento $\left(7^{\mathrm{a}}\right.$ e $8^{\mathrm{a}}$ séries). A aluna cursa um segmento por ano. Há um professor de Ciências e Matemática, professora de Português, professor de Inglês, professor de Educação Física, e uma professora de História e Geografia.

Em nossas incursões em instituições prisionais (presídio, penitenciária e APAC), observamos que acesso às salas de aula é diferente. No presídio e na penitenciária há normas de segurança observadas na saída e trajeto da cela à sala de aula: revistas, acompanhamento de agentes penitenciários que, inclusive, permanecem nos corredores próximos às salas de aula. Na APAC as mulheres do regime semiaberto dirigem-se sozinhas às salas de aula e não há normas de segurança mais rígidas. Há que se ressaltar, no entanto, que as mulheres que são encaminhadas para as APACs já passaram por rigoroso sistema de triagem em relação à segurança.

No regime fechado são os professores que se descolam para a sala de aula que funciona nesse espaço:

Pedagoga: - Porque o sistema fechado não,pode sair de forma alguma, né.

Entrevistadora: - Nem pra ir pra escola?

Pedagoga: - Nem pra ir ao banheiro no sistema aberto. Pra você ter uma ideia, nem na portinha só quando o juiz vai lá, ou a promotora que elas podem sair lá de dentro, mesmo assim ele não gosta, né? Então assim o sistema do fechado é fechado.Elas não podem de forma alguma ir pra fora [ir para o espaço do regime semi-aberto].

Assim, em um mesmo dia, em horários alternados, um mesmo professor atende separadamente aos dois grupos de alunas.

Com relação ao projeto pedagógico da instituição analisada, a pedagoga entrevistada afirma que não há um projeto específico que contemple a escola naquela instituição e segue-se o Projeto Pedagógico e orientações gerais sobre a EJA da rede municipal: "É o mesmo [projeto] da escola. A gente não tira, o único diferencial é o horário" (Pedagoga APAC).

Se o texto desses documentos "permanece o mesmo" de uma escola que funciona fora dos muros da prisão, o cotidiano da escola na prisão é atravessado por regulamentos, normas, ordenamentos, restrições espaciais, controle do tempo, sanções, vigilância e regras disciplinadoras e normalizadoras que ecoam o descrito por Michel Foucault em seu livro "Vigiar e punir: nascimento das prisões". (Foucault, 1987).

$\mathrm{Na}$ APAC não se praticam as mesmas normas rígidas de segurança de outras instituições: não há agentes penitenciários, não há revistas de policiais para as mulheres se dirigirem às salas de aula, a entrada das pessoas na instituição não segue normas rígidas, como revistas, por exemplo, e uma das recuperandas fica responsável pela portaria - entrada e saída de pessoas - mantendo inclusive as chaves. Mesmo assim, há uma vigilância e o "bom comportamento é valorizado", até mesmo determinando o acesso às aulas, pois para ir a escola é preciso "ter um bom comportamento. Tudo envolve, se der uma briguinha ela já tá de castigo. Então a gente respeita muito isso, os professores ficam de olho" (pedagoga).

É no cruzamento dessas duas escalas que buscamos compreender os relatos das mulheres entrevistadas: a escala das trajetórias individuais que, revelando as marcas da condição de classe e

${ }^{10} \mathrm{~A}$ classificação refere-se a um procedimento utilizado pelas escolas do sistema educacional brasileiro para alocar o/a estudante na série equivalente ao conhecimento que ele possui. Esta classificação pode se dar por meio do documento formal que é o histórico escolar ou por meio de uma avaliação aplicada pela escola. 
gênero (dificuldades para prosseguir os estudos, gravidez precoce, responsabilidade pelo sustento e educação dos filhos), são vivenciadas de maneira subjetiva; e a escala das condições de oferta da educação no sistema prisional, no Brasil e, especificamente, na escola da APAC pesquisada. Para realizar a leitura desse mapa em duas escalas, retomamos a teoria da relação com o saber proposta por Bernard Charlot.

Charlot $(2000,2005)$ propõe a compreensão do sujeito como, ao mesmo tempo, e inteiramente, um ser humano, um ser social e um ser singular. Um ser de desejo em um mundo compartilhado com outros sujeitos; que ocupa uma posição social cuja primeira instância é a família e atribui sentidos e significados singulares a si próprio e ao mundo, na construção de uma história singular. Para esse sujeito, aprender é uma necessidade que marca sua presença em um mundo produtor de saberes. Essa atividade é central no processo de construção do ser humano, que envolve tornar-se um membro da espécie humana (hominizar-se), tornar-se um ser humano único (singularizar-se) e tornar-se membro de uma comunidade, ocupando nela um lugar (socializar-se). Através da educação produz-se a si mesmo e é produzido pelo mundo. Portanto, o sujeito e sua história são sempre totalmente sociais e totalmente singulares, e o pertencimento a uma classe social é interpretado de maneira ativa pelo indivíduo, na construção de uma história da qual é sujeito. Em diálogo com a Sociologia da Educação de Pierre Bourdieu, o autor afirma que é preciso analisar as atividades que os indivíduos exercem,no contexto das posições sociais, para “... conquistar, para manter, para 'transmitir' essas posições e é preciso considerar também outras persepctivas do que simplesmente a de sua posição social" (Charlot, 2005, p.40, aspas do autor).

Frente à obrigação de aprender para ser, a qual, de acordo com o autor, é subjacente à condição humana, os sujeitos vivenciam diversos processos de aprender, nos quais estabecelem diferentes relações com diferentes saberes, diferentes relações com o aprender em contextos diversos.

A relação com o saber é o conjunto das relações que um sujeito estabelece com um objeto, um 'conteúdo de pensamento', uma atividade, uma relação interpessoal, um lugar, uma pessoa, uma situação, uma ocasião, uma obrigação, etc., relacionados de alguma forma ao aprender e ao saber - consequentemente, é também relação com a linguagem, relação com o tempo, com a atividade no mundo e sobre o mundo, relação com os outros e relação consigo mesmo, como mais ou menos capaz de aprender tal coisa, em tal situação (Charlot, 2005, p.45).

A relação com o saber é, portanto, constituída por um conjunto de relações empreendidas com diversas formas de aprender que variam de acordo com a situação colocada pelo tipo de saber e pelas circunstâncias nas quais ocorrem a aprendizagem. Essa noção opõe-se à análise "negativa", aquela que identifica os elementos que "faltam" ao sujeito para atingir a atitude adequada em relação à aprendizagem. Assim, é equivocado que nos preocupemos em encontrar "a" relação com o saber do sujeito, ignorando os diferentes espaços, situações e interações envolvidos no processo educativo do qual este sujeito participa. "A pesquisa sobre a relação com o saber deve analisar então os diferentes elementos que integram os processos construídos pelo sujeito nas diversas interações" (Charlot, 2001, p.15-16).

Remetendo-nos ao contexto dos dados discutidos neste artigo, podemos perguntar: que elementos integram os processos construídos pelas mulheres alunas da escola da APAC nas interações que vivenciam na escola? Tais elementos encontram-se, por um lado, em suas trajetórias escolares: em que medida puderam usufruir do direito à educação? De que maneira outras demandas - maternidade, trabalho, relações amorosas, relação com o mundo do crime, condições de acesso interferiram na sua "decisão" de abandonar a escola? O que aprendiam? Como se vêem como aprendizes (mais ou menos capazes de aprender)? Os elementos dos processos educativos das mulheres entrevistadas encontram-se também, por outro lado, nas possibilidades (ou limites) que 
encontram na prisão para continuar estudando: como se constitui a oferta? Como se organiza o currículo? Quem são e como atuam seus(suas) professores(as)?

Alguns desses elementos foram apresentados anteriormente. Na primeira seção, ficou claro que a escola na APAC significa possibilidade e limite da educação, oferta e negação do direito de estudar. Possibilidade e oferta na medida em que garante os anos finais do Ensino Fundamental, com a realização de atividades educativas escolares de maneira regular e com certificação. Limite e negação do direito na medida em que não oferece o Ensino Médio, está submetida às normas da prisão (as quais, muitas vezes, não coincidem com as possibilidades dos processos educativos).

$\mathrm{Na}$ apresentação sucinta que fizemos das mulheres entrevistadas, nesta seção, os elementos das trajetórias escolares estão delineados, mostrando a diversidade dos percursos escolares e da imagem que construíram de si mesmas. A seguir, prosseguimos com a apresentação do referencial teórico da relação com o saber proposto por Bernard Charlot para trazer à discussão outros elementos dos processos educativos.

\section{Mobilização, Atividade e Sentido}

A análise da relação com o saber leva o autor aos conceitos de mobilização, atividade e sentido: "o que é analisado aqui como relação funciona como um processo que se desenvolve no tempo e implica atividades" (Charlot, 2000, p. 54).Para haver atividade, o sujeito deve mobilizar-se e para isso, a situação deve apresentar sentido .

O conceito de mobilização remete à dinâmica interna necessária para aprender. Mobilizar-se é colocar-se em movimento. "Mobilizar é por recursos em movimento. Mobilizar-se é reunir suas forças, para fazer uso de si próprio como recurso" (Charlot, 2000, p.55). A definição da mobilização envolve o conceito de atividade, o autor afirma que o sujeito

... mobiliza-se, em uma atividade, quando investe nela, quando faz uso de si mesmo como de um recurso, quando é posta em movimento por móbeis que remetem a um desejo, um sentido, um valor. A atividade possui, então, uma dinâmica interna. Não se deve esquecer, entretanto, que essa dinâmica supõe uma troca com o mundo, onde encontra metas desejáveis, meios de ação e outros recursos que não ela mesma (Charlot, 2000, p.55). Segundo o autor, a adoção do termo atividade tem a intenção de ressaltar a presença de um sujeito que a realiza. Sujeito, como vimos, que se mobiliza, coloca-se em movimento em função de determinadas atividades. Para a compreensão dessa dinâmica, Charlot utiliza ainda o conceito de sentido.

Esse conceito é explicado pelo autor por uma tripla definição: a possibilidade do estabelecimento de relações em um sistema ou conjunto, a possibilidade de estabelecimento de relações com outros aspectos ou fatos da vida do sujeito e a produção de inteligibilidade sobre algo. Assim, tem sentido "o que é comunicável e pode ser entendido em uma troca com os outros. Em suma, o sentido é produzido por estabelecimento de relação, dentro de um sistema, ou nas relações com o mundo ou com os outros" (Charlot, 2000, p.57).

Esses três conceitos foram adotados na leitura que fizemos dos relatos produzidos pelas mulheres nas entrevistas.

Podemos iniciar esta reflexão perguntando: Ao frequentarem a escola da APAC, em relação a quê e de que maneiras as entrevistadas mobilizam-se? Como fazem "uso de si" nesses processos? Nos relatos produzidos por elas, encontramos a mobilização em relação a "uma vida normal” (aqui, o movimento é em direção ao exterior, àquilo que poderão usufruir quando estiverem em liberdade, se tiverem avançado na sua escolaridade) e também em relação ao aprender na escola, aprender 
conteúdos, aprender habilidades tipicamente escolares (nesse caso, o movimento é centrípeto, ou seja, elas se movem em direção aos próprios saberes escolares). Vejamos as duas situações:

"Tô perto de sair, vou sair dia 28 de agosto, agora, vou voltar estudar e pretendo seguir minha vida normal! Uma vida de um ser humano normal"(Cândida).

"É o estudo, é muito bom estudar. Hoje eu vejo a falta que faz, porque se o cê quiser um trabalho cê tem que ter até o $3^{\circ}$, pra você conseguir um emprego então o estudo faz falta sim. Hoje eu posso ver que realmente faz falta pra gente"(Vilma).

"Eu acho que eu mudei, porque agora eu penso mais pra frente. Penso estudar mais, crescer mais pra dá, dá uma vida boa pro meu filho"(Cecília).

Essas falas mostram uma mobilização em relação ao futuro, para o qual a educação é uma

trilha segura, ou uma exigência externa. As falas seguintes mostram que existe também a mobilização em relação ao saber escolar. E isto as mobiliza em busca do saber escolar, mas não é somente a remição o que as mobiliza. O saber escolar, o aprender o que não sabia é também muito importante para elas que foram durante muito tempo privadas do acesso ao conhecimento e do acesso ao universo que o domínio do conhecimento possibilita.

Cândida, por exemplo, demonstra enorme satisfação em aprender, e isso se destaca mesmo quando respondia a uma pergunta sobre a remição da pena por dias estudados:

"Lógico que queria minha remição, ia me ajudar bastante no meu processo. E outra eu queria aprender, eu queria aprender o que eu não sabia, muitas coisas eu não sabia que hoje eu já sei. Por exemplo: interpretar texto. Eu nem nunca imaginava que eu sabia interpretar um texto" (Cândida).

Também na matemática, disciplina em relação à qual afirma ter mais dificuldade, Cândida demonstra a satisfação em perceber que está aprendendo: "Aí é igual três elevado a dois, aí eu vou somar o três duas vezes, aí vai ser conta de vezes. Aí eu somei duas vezes. Eu não sabia, nem imaginava. Entendeu? Agora eu já sei!"

Cecília já concluiu o ensino fundamental e participava de algumas aulas, "só pra pegar algumas coisas que tem muito tempo que eu não estudo. Eu queria né? Pra quando eu fosse pro semiaberto eu ir pra escola já lembrando de algumas coisas que eu esqueci."

Ao comentar sobre outras alunas da escola é que Cecília revela seu encantamento em relação ao aprender:

“Tem muitas que tão aqui que não tinham nem... que não sabiam nem ler e escrever, que aprenderam muita coisa aqui mesmo. Tem gente aqui que não sabia ler já junta as letrinhas. Assim.... elas não falam pra gente, elas falam assim quietinha, baixinho, eu que fico prestando atenção: - Oh, aprendeu! Aí elas ficam rindo à toa (risos). Eu gosto de ver quando elas estão juntando as letrinhas também, é bonitinho" (Cecília).

Ângela, quando perguntada sobre o que mais gosta na escola, responde: "experiência". Ao explicar sua resposta, fala do envolvimento com as "histórias novas" de cada dia: "Acho muito interessante porque cada dia, principalmente de matemática, é... é principalmente história e geografia, cada dia é uma história nova. Sabe? Aí você se envolve naquilo ali e tal, eu acho muito bom"( Ângela).

A questão da mobilização aparece na discussão de Maeyer (2013) como “...reconciliação com o ato de aprender, às vezes até com a alegria de aprender”, e é apontada pelo autor como “... o objetivo último que a prisão pode ter. (Maeyer, 2013, p.48).

Além da mobilização, podemos ler os relatos produzidos nas entrevistas pela ótica do conceito de sentido. Lembrando a definição de Charlot apresentada anteriormente, perguntamos: o quê faz sentido na educação escolarizada vivenciada na APAC? Apesar da mobilização em relação ao aprender, as entrevistadas não se referiram aos conteúdos escolares como elementos que "fizessem sentido", ajudassem a compreender o mundo, tivessem relação com algo que fizessem ou que 
soubessem anteriormente. O que parece trazer maneiras diferentes de entender a vida, ou de viver, é a relação com os (as) professores (as), mais especificamente, o fato de que as professoras da escola as tratam bem, interessam-se por suas vidas e as veem como capazes de aprender. Vejamos alguns exemplos:

Ao ser perguntada sobre o que mais gostava na escola, Cândida inicialmente faz referência ao conteúdo, para a seguir enfatizar a relação com a professora: "Ah, eu gosto de tudo né? O meu problema mais é na matemática, a professora é maravilhosa. A Mariza, não sei se vocês conhecem.. Ela tem assim, explica direitinho, explica de novo e eu tô pegando. Os professores que dão aula aqui são maravilhosos, tratam a gente super bem como pessoas mesmo, pra eles assim, nós não somos nem recuperandas"(Cândida).

No caso de Cândida, a satisfação em relação à aprendizagem da interpretação de textos começa pelo reconhecimento de que ela sabia interpretar textos, o que se inicia pela intervenção da professora, em uma atitude de valorização da aluna: "E a Sueli (professora) falou assim: - Cristina cê tá ótima na interpretação de texto. Eu falei assim: ah, Sueli, pára.... E ela tá me ensinando os parágrafos direitinho aonde eu posso por ponto, aonde eu não posso."

O diálogo abaixo, partindo da pergunta da entrevistadora, mostra também como o interesse das professoras é o que parece fazer sentido na escola:

Entrevistadora:- E como é na sala?

Cândida: - Ah o professor chega, dá boa tarde, pergunta se tá tudo bem... E se a gente tem alguma novidade do nosso processo a gente conta pra eles, eles escutam.

Entrevistadora:- Que novidades?

Cândida: - Igual mesmo dia 16 eu tenho um fórum[audiência]. Aí eu já chego assim: -Ah, professora! É que eu fiquei sabendo né? Então eu já chego a professora: - dia 16 eu tenho um fórum! Aí eles ficam alegres da mesma forma que a gente fica! Eles são gente boa!

Aspectos semelhantes estão presentes no relato de Aline:

"Eu encarei todo um mundo de novo de tudo que eu tinha me esquecido, mas aos poucos eu fui lembrando. E é muito bom! São assim professores que vem sem o menor receio de tá vindo, apesar que tá sabendo que tá mexendo com preso não é fácil mas vem de coração aberto, disposto a ajudar, oferecer um ombro amigo, a ser mais que professor, isso é importante pra gente." (Aline).

A questão do sentido aparece como o aspecto central da educação nas prisões: "identificar e hierarquizar as aprendizagens para lhes dar um sentido: para que elas possam lhe oferecer possibilidades de escolha com conhecimento de causa; para que a faculdade de escolher reencontre seu campo de ação, a saber o eu-aprisionado mas aprisionado por um certo tempo apenas." (Maeyer, 2013, p.39).

Finalmente, poderíamos nos perguntar sobre as atividades desenvolvidas pelas mulheres na escola. Nas entrevistas, elas não abordam as atividades que realizam na escola, enfatizando, como vimos, qualidades e atitudes dos professores e professoras. Outros momentos do processo de coleta de dados fornecem elementos que podem ajudar a entender essa "ausência". As visitas à instituição e as conversas que tivemos com as recuperandas nos fizeram ver que as possibilidades de atividades educativas que envolvem discussão de temas, argumentação e pesquisa não encontram espaço na escola, porque não tem lugar na instituição prisional.

$\mathrm{Na}$ entrevista realizada com a pedagoga, aparece a dificuldade da escola em abordar temas da vida das alunas: é preciso "tomar bastante cuidado, porque não é não é igual a uma sala comum da EJA". A pedagoga argumenta que em uma sala de EJA, normalmente se utilizam exemplos da vida cotidiana para compor o cenário da aula - referência a trabalho, família, igreja etc..Para ela, a abordagem desses temas poderia "magoar" e "agredir" as alunas. Cita o exemplo de um professor que "só falava de cadeia", do qual as alunas reclamaram. Conclui que elas "... não querem ficar 
presas ao mundo que elas estão querendo deixar para trás". Percebemos aí um distanciamento em relação às discussões do campo da EJA nas quais são recorrentes as reflexões sobre a necessidade de se considerar, no processo de escolarização, as práticas e os saberes de alunos e alunas da EJA e a recomendação explícita de se tratar esses sujeitos como pessoas adultas. $\mathrm{Na}$ escola da prisão, observamos, pelas especificidades de uma escola em um contexto de encarceramento, um modo de pensar que permeia o cotidiano da escola, segundo o qual a vida de mulheres [e de homens] deve ser evitada, produzindo-se, deste modo saberes e fazeres na contramão dos avanços no campo da EJA. Ignora-se, assim, que "o[a] detento[a] não chega do nada na prisão e nos cursos. Ele[a] possui uma experiência compartilhada com outros detentos com os quais tem um universo de exclusão comum.” (Maeyer, 2013, p.39).

Além disso, as relações interpessoais na escola da APAC seguem padrões próprios da instituição prisional, que implicam vigilância e desconfiança, entre as próprias recuperandas. Isso dificulta a realização de atividades que fujam de uma relação de aprendizagem verticalizada, que envolveria diálogo e troca de saberes. Há uma dificuldade das alunas conversarem entre si, ou de se estabelecer uma relação dialógica entre docentes e discentes: "Então assim, é todo um cuidado porque qualquer coisinha que você fala ela leva contra você. E é isso que elas reclamam lá dentro essa pressão, né de uma contra a outra. Se você fala alguma coisa elas levam lá na direção de uma maneira diferente e aí cria toda confusão".

Parece haver, então, um impedimento para a realização de atividades que possibilitem a construção de sentido, o cotidiano escolar está preso a atividades "inofensivas" e distanciadas da realidade.

A EJA reconhece a importância de que a vida dos sujeitos se faça presente nas práticas educativas. Na escola em instituições prisionais parece não haver espaço para a vida: por um lado, a vida anterior não pode ser evocada, pois traria a realidade da infração e das perdas a ela vinculadas. Por outro lado, impõe-se o silenciamento sobre as angústias, as necessidades, as insatisfações da vida presente.

\section{Conclusão}

Em nossas discussões iniciais assinalamos os avanços legais em relação à garantia do direito à educação no contexto de privação de liberdade. Há hoje a deliberação de um arcabouço legal constituído tanto pelo Conselho Nacional de Política Criminal e Penitenciária quanto pelo Conselho Nacional de Educação. Neste arcabouço destacamos que já se caminha no Brasil para a construção de um Plano Estratégico de Educação no Sistema Prisional ${ }^{11}$ que tem como objetivo ampliar e qualificar a educação oferecida nos estabelecimentos penais.

Isso certamente decorre de um outro avanço importantíssimo que se instala no seio da sociedade, que é o reconhecimento das possibilidades geradas pela educação no contexto de privação de liberdade.Consideramos ainda que este reconhecimento ultrapassa o campo do já conhecido discurso da ressocialização e chega ao campo do reconhecimento da educação como um direito fundamental.

${ }^{11}$ Decreto n. 7.626/2011 da presidência da república. Disponível em http://www.planalto.gov.br/ccivil 03/ Ato2011-2014/2011/Decreto/D7626.htm 
Vimos que a despeito das Diretrizes Nacionais para a oferta de educação nos estabelecimentos penais ${ }^{12}$ definirem no art. $3^{\circ}$ que a oferta de educação no contexto prisional deve: “ resultar do processo de mobilização, articulação e gestão dos Ministérios da Educação e Justiça, dos gestores estaduais e distritais da Educação e da Administração Penitenciária, dos Municípios e da sociedade civil" constatamos que entre três instituições pesquisadas, mesmo existindo demanda, em uma não havia oferta formal de educação básica e em uma outra não era ofertado o ensino médio.

Nessas discussões outro fato a considerar diz respeito a remição de parte da pena pelo estudo $^{13}$ para as mulheres que cumprem regime fechado ou semiaberto. Nesse sentido, é importante observar que no Estado de Minas Gerais a modalidade de ensino oferecida nas prisões é a Educação de Jovens e Adultos (EJA) cuja matriz curricular prevê uma carga horária diária de atividade escolar bem inferior a quatro horas (em torno de duas horas diárias de estudo). Isto representa um prejuízo para as pessoas privadas de liberdade em razão do pouco aproveitamento em relação ao tempo que é destinado em sua maior parte às atividades ligadas ao trabalho, muitas vezes desqualificado, e com baixa remuneração. Fica assim reduzida a parte do tempo destinada à educação, cujo aligeiramento não tem sentido, pois a prisão é um espaço no qual as pessoas possuem todo o tempo disponível e que poderia certamente ser destinado a processos de escolarização pautados em outra lógica. Além disso, é importante observar que como é pequena a carga horária destinada à escola e a remição se dá em uma proporção de um dia para cada doze horas de estudo, cumpridos no mínimo em três dias; para remir um dia serão necessários mais de uma semana de estudo.

Assim, "como tem acontecido em muitos momentos e áreas de atuação na história contemporânea do Brasil, o arcabouço legal e normativo constitui um referencial mais avançado que a prática na maioria dos sistemas prisionais estaduais" (Ireland, 2011.p.16).

Em nossas reflexões construídas no movimento desta investigação constatamos a ampliação do acesso à educação das mulheres pela oferta de EJA nas instituições prisionais. Entretanto, tal oferta não se estende a todas as 03 instituições analisadas e mesmo quando ocorre, nesse contexto, o acesso ainda não se faz de modo igualitário para todas as mulheres, pelos cerceamentos próprios da prisão. Temos refletido sobre os aprisionamentos dessa escola (com seus códigos e regras de conduta) que ecoam nas práticas educativas: nas relações docentes e discentes, nas relações das alunas entre si, nas formas de organização desse espaço, nas diferentes funções e sentidos da escolarização (para o sistema prisional e para as mulheres).

Ao trazer à cena as narrativas dessas mulheres, temos acesso à perspectiva dos sujeitos que vivenciam, em meio à situação de privação da liberdade, a experiência escolar. Os conceitos de mobilização, atividade e sentido permitem uma leitura dessa perspectiva, que apresenta as

\footnotetext{
12 Disponível em: http://portal.mec.gov.br/index.php?option $=$ com docman\&task $=$ doc download\&gid $=10028 \& I t e m i d=$ Acesso em 26 de junho de 2013.

${ }^{13}$ A Lei 12433 de 29 de junho de 2011 (http://www.planalto.gov.br/ccivil_03/_ato20112014/2011/lei/112433.htm) com vigência a partir desta data de sua publicação, alterou especialmente os artigos 126 da Lei de Execução Penal (Lei 7. 210 de 11 de julho de 1984) que passou contemplar a remição de parte do tempo de execução da sentença pelo estudo. A aprovação dessa lei representa mais uma importante etapa no processo de consolidação do direito à educação das pessoas privadas da liberdade . No novo texto do art $126 \$ 1^{\circ}$ inciso II da Lei 7.210/1984, a contagem do tempo é com abatimento de um dia para cada 12 horas de frequência escolar, em atividades de ensino, superior, fundamental, médio e profissionalizante ou requalificação profissional cumpridas no mínimo em 3 dias.
} 
imbricações entre as trajetórias escolares anteriores e as vivências escolares na prisão e os descompassos entre as possibilidades abertas pelos processos educativos e os cerceamentos da condição de privação de liberdade. Essas narrativas apontam, também, para o estabelecimento, pelas mulheres, de diferentes formas de "relação com o saber", sustentadas pela mobilização em relação ao aprender e vivenciadas nos limites impostos pelo contexto prisional.

Mesmo nesses limites permanece aberta a possibilidade de construção de novos sentidos e o desafio de que se estabeleça nesse espaço

a relação entre estudar e manter as características humanas da produção de conhecimento, de tomada de decisões autônomas e de sonhar, retomando o sentido da educação como "manifestação exclusivamente humana", que reconhece as pessoas como "seres inconclusos, conscientes de sua inconclusão, e seu permanente movimento de busca do ser mais" (Graciano, 2008, p. 127,128, aspas da autora).

\section{Referencias}

Brasil (2010). Senado Federal. LEP: Lei de Execução Penal- Lei no 7.210 de 11 de julho de 1984. Disponível em: http://www6.senado.gov.br/legislacao. Acesso em: 09/09/ 2010. Brasil (2008). Sistema Penitenciário no Brasil: dados consolidados. Brasília, 2008. Disponível em: www.portal.mi.gov.br/data/pages . Acesso em: 25/09/ 2012.

Brasil (2010). Resolução CNE/CEB 2/2010. Diário Oficial da União, Brasília, 20 de maio de 2010, Seção 1, p. 20.

Carreira, D. (2009).Relatoria Nacional para o Direito Humano à Educação: Educação nas Prisões Brasileiras. São Paulo: Plataforma DhESCA. Brasil. Disponível em: http://www.dhescbrasil.org.br Acesso em: 06/04/ 2012.

Charlot, B. (1999).Rapport au savoir en milieu populaire. Une recherche dans les lycées professionnels de banlieue. Paris: Anthropos.

Charlot, B. (2000).Relação com o saber. Elementos para uma teoria. Porto Alegre: Artes Médicas Sul.

Charlot, B. (2001). Os jovens e o saber:perspectivas mundiais.Porto Alegre: Artmed Editora.

Charlot. B. (2005). Relação com o saber: Formação dos professores e globalização. Questões para a educação hoje. Porto Alegre: Artmed.

Colares, L.B.Correia; Chies, L.A.B. (2010). Mulheres nas so(m)bras: invisibilidade, reciclagem e dominação viril em presídios masculinamente mistos. Revista Estudos Feministas, 18(2), 407423. Disponível em <http://www.scielo.br/scielo. Consultado em 10/07/2013

Foucault, M.(1987).Vigiar e Punir: nascimento da prisão. Petrópolis, Vozes. Graciano, M. (2005).A educação como direito humano:a escola na prisão. 165f. Dissertação (Mestrado em Educação) - Faculdade de Educação, Universidade de São Paulo, São Paulo.

Graciano, M.; Schilling, F.(2008).A educação na prisão: hesitações, limites e possibilidades. Estudos de Sociologia, 13(25) 111-132.

Ireland, T.D. (2009) .Vinte anos de Educação para Todos (1990-2009): um balanço da educação de jovens e adultos no cenário internacional. Em Aberto, 22 (82) 43-57.

Ireland, T. D. Educação em prisões no Brasil: direito, contradições e desafios. In: Ireland, T.D. (org.) (2011). Educação em prisões. Em Aberto, 24 ( 86) 19-39.

Louro, G. L. (1997). Gênero, Sexualidade e Educação: Uma perspectiva pós-estruturalista. Petrópolis: Vozes.

Louro, G. L. (2007). Gênero, sexualidade e educação: das afinidades políticas às tensões teórico-metodológicas. Educação em revista, 46 (1)201-218. 
Maeyer, Marc De. (2013). A educação na prisão não é uma mera atividade. Educação \& Realidade, 38(1), 33-49. Recuperado em 15 de julho de 2013, de http://www.scielo.br/scielo.php.

Nonato, E. M. N.(2010).Educação de mulheres em situação prisional: experiência que vem do sul, no processo de reinvenção social. 198f. Tese (Doutorado em Ciências Sociais). Universidade do Vale do Rio dos Sinos, Porto Alegre.

Nonato, E. M. N.Educação de mulheres em situação de privação de liberdade. In: Ireland, T.D. (org.) (2011). Educação em prisões. Brasília: INEP; Brasília: Em Aberto, 24 (86) 127-140.

Nogueira, V. L. (2003).Educação de Jovens e Adultos e Gênero: Um diálogo imprescindível à elaboração de políticas educacionais destinadas às mulheres das camadas populares. In: Soares, Leôncio José (org.) Aprendendo com a diferença: Estudos e Pesquisas em Educação de Jovens e Adultos. Belo Horizonte: Autêntica, p. 65-90.

Perrot, M.(2005). As mulheres e os silêncios da História. Bauru, SP: EDUSP.

TJMG (2009). Tribunal de Justiça do Estado de Minas Gerais. Projeto novos rumos da execução penal. Disponível em www.tjmg.jus.br Acesso em 05/05/2012.

Sauer, A.H.; Julião, E. F.(2012). A educação para jovens e adultos em situação de restrição e privação de liberdade no Brasil: questões, avanços e perspectivas. Documento referência. Seminário Educação nas Prisões. Brasília/DF - CNE - 23 de Abril de 2012. Disponível em portal.mec.gov.br/ Acesso em 12/12/2012.

Scott, J. (1990) Gênero: uma categoria útil de análise histórica. Educação e Realidade, 20 (2) 5-22.

Souza, M. C. R. F.(2008) Gênero e matemática(s): jogos de verdade nas práticas de numeramento de alunos e alunas da Educação de Pessoas Jovens e Adultas. 319p. Tese (Doutorado em Educação) - Universidade Federal de Minas Gerais, Belo Horizonte.

Souza, M. C. R. F.; Fonseca, M. C. F. R. (2008). Relações de Gênero, práticas de cuidado e Educação de Pessoas Jovens e Adultas. In: $31^{a}$ Reunião anual da ANPEd, Caxambu,. Disponível em: http://www.anped.org.br/reunioes/31 ra/1trabalho/GT18-4457--Int.pdf

Souza, M. C. R. F.; Fonseca, M. C. F. R. .(2010). Relações de Gênero, Educação Matemática e Discurso: enunciados sobre homens, mulheres e matemática. Belo Horizonte: Autêntica, 149 p.

Souza, M. C. R. F.et al.(2012).Educação de mulheres adultas na prisão: o currículo como prática normalizadora. Anais X Colóquio Sobre Questões Curriculares/VI Colóquio Luso Brasileiro de Currículo. Belo Horizonte.

Souza, M. C. R. F.; Caetano, C. S.; Rosa, S. F. (2012).Educação de mulheres em situação de aprisionamento: reflexões sobre o perfil social e o direito à educação. In: $35^{a}$ Reunião Anual da ANPEd. Porto de Galinhas. Disponível em: http://35reuniao.anped.org.br/images/stories/posteres/GT18/GT18-1501 int.pdf.

UNESCO (1999). V CONFINTEA - Conferência Internacional de Educação de Adultos. Declaração de Hamburgo:agenda para o futuro. Brasília, DF: SESI/UNESCO.

UNESCO (2009) VI CONFINTEA - Conferência Internacional de Educação de Adultos. Marco de Ação de Belém. Brasília, DF. Brasil.

Walkerdine, V. (2003).Couting Girls Out: Girls and Mathematics. (New Edition). Londres: Virago.

Yamamoto, A. et al (2010).Cereja Discute: educação em prisões. São Paulo: Alfa Sol: Cereja. 


\section{Sobre as Autoras}

\section{Maria Celeste Reis Fernandes Souza}

Email: celeste.br@gmail.com

Doutora em Educação pela Universidade Federal de Minas Gerais - UFMG

Atuou como docente no Ensino Superior em atividades de ensino, pesquisa, extensão e gestão acadêmica. Seus estudos concentram-se na área da Educação de Pessoas Jovens e Adultas- EJA, Educação Matemática, Relações de Gênero e Estudos Territoriais em interface com o campo da Educação. Atua em projetos de educação social no campo da EJA. Atualmente é Secretária Adjunta de Educação na Secretária Municipal de Educação de Governador Valadares contribuindo para a consolidação da Escola em Tempo Integral.

\section{Maria Gabriela Parenti Bicalho}

Email: gpbicalho1@uol.com.br

Pós-doutora em Educação pela Universidade Federal de Sergipe, doutora em Educação pela Universidade Federal de Minas Gerais.No ensino, suas atividades estão centradas na Sociologia da Educação e na Metodologia da Pesquisa. Desenvolve pesquisas sobre a relação com o saber de estudantes do ensino superior e sobre Educação e Território.Possui experiência em projetos de extensão universitária na EJA, e realizou pesquisas nesse campo como docente da Universidade Vale do Rio Doce - UNIVALE.

\section{Eunice Maria Nazareth Nonato}

Email: eunicenazarethe@,hotmail.com

Doutora em Ciências Sociais pela Universidade Vale do Rio dos Sinos - UNISINOS. Professora do Curso de Direito do Centro Universitário Metodista Izabela Hendrix, onde também atua no Observatório de Direitos Humanos. Possui experiência na docência e em diversos espaços de gestão com atuação no âmbito da educação pública e privada. Trabalha principalmente com os seguintes temas: educação em contexto urbano, gestão em educação, educação em espaço prisional e sócio educativo. Integra o Comitê Estadual de Educação em Direitos Humanos de Minas Gerais.

\section{Sobre as Editoras Convidadas}

\section{Sandra Regina Sales}

Professora do Programa de Pós-Graduação em Educação, Contextos Contemporâneos e Demandas Populares (PPGEduc) na linha de pesquisa Educação e Diversidades Etnico-Raciais e do Departamento Educação e Sociedade da Universidade Federal Rural do Rio de Janeiro. Email: sandrasales@,ufrri.br A editora é pesquisadora nos campos da Educação de Jovens e Adultos, Mídia e Educação e Políticas de Ação Afirmativa no Ensino Superior. Integra o Grupo de Pesquisa (CNPq) Políticas de trans-formação: pesquisas em educação e comunicação, do qual é líder, e o Laboratório de Estudos Afro-brasileiros - LEAFRO. Atualmente desenvolve as pesquisas A EJA e a diversidade na mídia: uma análise das representações dos sujeitos, dos atores e das politicas educacionais nas revistas semanais brasileiras e Que educação para que cidadão? Discursos influentes na Educação de Jovens e Adultos no Brasil (1995-2013). É coorganizadora do livro Educação de Jovens e Adultos: políticas e práticas educativas (2011) e tem publicado artigos em revistas e capítulos de livros nas áreas de pesquisa nas quais atua. 


\title{
Jane Paiva
}

Professora do Programa de Pós-Graduação em Educação (ProPEd), na Linha de Pesquisa Educação Inclusiva e Processos Educacionais e do Curso de Pedagogia da Faculdade de Educação da Universidade do Estado do Rio de Janeiro (UERJ).

Email: janepaiva@terra.com.br

A editora é pesquisadora no campo da educação de jovens e adultos, atuando na formação de pedagogos e de novos pesquisadores - mestres e doutores. É líder do Grupo de Pesquisa (CNPq) Aprendizados ao longo da vida: sujeitos, políticas e processos educativos. No momento desenvolve a pesquisa integrada (com a Universidade Estadual de Campinas e a Universidade Federal de Juiz de Fora) Diagnóstico da qualidade de ensino na educação de jovens e adultos: um estudo de caso nos municípios de Campinas, Juiz de Fora e Rio de Janeiro, financiada pelo Edital Observatório da Educação, da CAPES/INEP; e coordena as ações do projeto de pesquisa e extensão do Centro de Referência e Memória da Educação Popular e da Educação de Jovens e Adultos (CReMEJA). Autora de artigos em revistas e capítulos de livros no campo.

\section{DOSSIÊ}

EDUCAÇÃO DE JOVENS E ADULTOS; APRENDIZAGEM NO SÉCULO 21

\section{arquivos analíticos de políticas educativas}
Volume 21 Número 76
Setembro $23^{\text {rd }}, 2013$
ISSN 1068-2341

\begin{abstract}
(c)
SORERIGHIS RESERVED O Copyright e retido pelo/a o autor/a (ou primeiro co-autor) que outorga o direito da primeira publicação à revista Arquivos Analíticos de Políticas Educativas. Más informação da licença de Creative Commons encontram-se em http://creativecommons.org/licenses/by-nc-nd/2.5. Qualquer outro uso deve ser aprovado em conjunto pelo/s autor/es e por AAPE/EPAA. AAPE/EPAA é publicada por Mary Lou Fulton Institute Teachers College da Arizona State University. Os textos publicados em AAPE são indexados por CIRC (Clasificación Integrada de Revistas Científicas, Espanha) DIALNET (Espanha),Directory of Open Access Journals, Education Full Text (H.W. Wilson), EBSCO Education Research Complete, , ERIC, , QUALIS A2 (Brasil), SCImago Journal Rank; SCOPUS, SOCOLAR (China). Contribua com comentários e sugestões a http://epaa.info/wordpress/ ou para Gustavo E. Fischman fischman@,asu.edu.
\end{abstract}

Curta a nossa comunidade EPAA's Facebook https://www.facebook.com/EPAAAAPE e Twitter feed@epaa_aape. 


\section{arquivos analíticos de políticas educativas conselho editorial}

Editor: Gustavo E. Fischman (Arizona State University) Editores Associados: Rosa Maria Bueno Fisher e Luis A. Gandin

(Universidade Federal do Rio Grande do Sul)

Dalila Andrade de Oliveira Universidade Federal de Minas Gerais, Brasil

Paulo Carrano Universidade Federal Fluminense, Brasil

Alicia Maria Catalano de Bonamino Pontificia Universidade Católica-Rio, Brasil

Fabiana de Amorim Marcello Universidade Luterana do Brasil, Canoas, Brasil

Alexandre Fernandez Vaz Universidade Federal de Santa Catarina, Brasil

Gaudêncio Frigotto Universidade do Estado do Rio de Janeiro, Brasil

Alfredo M Gomes Universidade Federal de Pernambuco, Brasil

Petronilha Beatriz Gonçalves e Silva Universidade Federal de São Carlos, Brasil

Nadja Herman Pontificia Universidade Católica -Rio Grande do Sul, Brasil

José Machado Pais Instituto de Ciências Sociais da Universidade de Lisboa, Portugal

Wenceslao Machado de Oliveira Jr. Universidade Estadual de Campinas, Brasil
Jefferson Mainardes Universidade Estadual de Ponta Grossa, Brasil

Luciano Mendes de Faria Filho Universidade Federal de Minas Gerais, Brasil

Lia Raquel Moreira Oliveira Universidade do Minho, Portugal

Belmira Oliveira Bueno Universidade de São Paulo, Brasil

António Teodoro Universidade Lusófona, Portugal

Pia L. Wong California State University Sacramento, U.S.A

Sandra Regina Sales Universidade Federal Rural do Rio de Janeiro, Brasil

Elba Siqueira Sá Barreto Fundação Carlos Chagas, Brasil

Manuela Terrasêca Universidade do Porto, Portugal

Robert Verhine Universidade Federal da Bahia, Brasil

Antônio A. S. Zuin Universidade Federal de São Carlos, Brasil 


\section{education policy analysis archives editorial board}

Editor Gustavo E. Fischman (Arizona State University)

Associate Editors: Audrey Amrein-Beardsley (Arizona State University), Rick Mintrop, (University of California, Jeanne M. Powers (Arizona State University)

Jessica Allen University of Colorado, Boulder

Gary Anderson New York University

Michael W. Apple University of Wisconsin, Madison

Angela Arzubiaga Arizona State University

David C. Berliner Arizona State University

Robert Bickel Marshall University

Henry Braun Boston College

Eric Camburn University of Wisconsin, Madison

Wendy C. Chi* University of Colorado, Boulder

Casey Cobb University of Connecticut

Arnold Danzig Arizona State University

Antonia Darder University of Illinois, UrbanaChampaign

Linda Darling-Hammond Stanford University

Chad d'Entremont Strategies for Children

John Diamond Harvard University

Tara Donahue Learning Point Associates

Sherman Dorn University of South Florida

Christopher Joseph Frey Bowling Green State University

Melissa Lynn Freeman* Adams State College

Amy Garrett Dikkers University of Minnesota

Gene V Glass Arizona State University

Ronald Glass University of California, Santa Cruz

Harvey Goldstein Bristol University

Jacob P. K. Gross Indiana University

Eric M. Haas WestEd

Kimberly Joy Howard* University of Southern California

Aimee Howley Ohio University

Craig Howley Ohio University

Steve Klees University of Maryland

Jaekyung Lee SUNY Buffalo
Christopher Lubienski University of Illinois, UrbanaChampaign

Sarah Lubienski University of Illinois, UrbanaChampaign

Samuel R. Lucas University of California, Berkeley

Maria Martinez-Coslo University of Texas, Arlington

William Mathis University of Colorado, Boulder

Tristan McCowan Institute of Education, London

Heinrich Mintrop University of California, Berkeley

Michele S. Moses University of Colorado, Boulder

Julianne Moss University of Melbourne

Sharon Nichols University of Texas, San Antonio

Noga O'Connor University of Iowa

João Paraskveva University of Massachusetts, Dartmouth

Laurence Parker University of Illinois, UrbanaChampaign

Susan L. Robertson Bristol University

John Rogers University of California, Los Angeles

A. G. Rud Purdue University

Felicia C. Sanders The Pennsylvania State University Janelle Scott University of California, Berkeley

Kimberly Scott Arizona State University

Dorothy Shipps Baruch College/CUNY

Maria Teresa Tatto Michigan State University

Larisa Warhol University of Connecticut

Cally Waite Social Science Research Council

John Weathers University of Colorado, Colorado Springs

Kevin Welner University of Colorado, Boulder

Ed Wiley University of Colorado, Boulder

Terrence G. Wiley Arizona State University

John Willinsky Stanford University

Kyo Yamashiro University of California, Los Angeles

* Members of the New Scholars Board 


\section{archivos analíticos de políticas educativas consejo editorial}

Editor: Gustavo E. Fischman (Arizona State University)

Editores. Asociados Alejandro Canales (UNAM) y Jesús Romero Morante (Universidad de Cantabria)

Armando Alcántara Santuario Instituto de Investigaciones sobre la Universidad y la Educación, UNAM México

Claudio Almonacid Universidad Metropolitana de Ciencias de la Educación, Chile

Pilar Arnaiz Sánchez Universidad de Murcia, España

Xavier Besalú Costa Universitat de Girona, España Jose Joaquin Brunner Universidad Diego Portales, Chile

Damián Canales Sánchez Instituto Nacional para la Evaluación de la Educación, México

María Caridad García Universidad Católica del Norte, Chile

Raimundo Cuesta Fernández IES Fray Luis de León, España

Marco Antonio Delgado Fuentes Universidad Iberoamericana, México

Inés Dussel FLACSO, Argentina

Rafael Feito Alonso Universidad Complutense de Madrid, España

Pedro Flores Crespo Universidad Iberoamericana, México

Verónica García Martínez Universidad Juárez Autónoma de Tabasco, México

Francisco F. García Pérez Universidad de Sevilla, España

Edna Luna Serrano Universidad Autónoma de Baja California, México

Alma Maldonado Departamento de Investigaciones Educativas, Centro de Investigación y de Estudios Avanzados, México

Alejandro Márquez Jiménez Instituto de Investigaciones sobre la Universidad y la Educación, UNAM México

José Felipe Martínez Fernández University of California Los Angeles, USA
Fanni Muñoz Pontificia Universidad Católica de Perú

Imanol Ordorika Instituto de Investigaciones Economicas - UNAM, México

Maria Cristina Parra Sandoval Universidad de Zulia, Venezuela

Miguel A. Pereyra Universidad de Granada, España

Monica Pini Universidad Nacional de San Martín, Argentina

Paula Razquin UNESCO, Francia

Ignacio Rivas Flores Universidad de Málaga, España

Daniel Schugurensky Arizona State University

Orlando Pulido Chaves Universidad Pedagógica Nacional, Colombia

José Gregorio Rodríguez Universidad Nacional de Colombia

Miriam Rodríguez Vargas Universidad Autónoma de Tamaulipas, México

Mario Rueda Beltrán Instituto de Investigaciones sobre la Universidad y la Educación, UNAM México

José Luis San Fabián Maroto Universidad de Oviedo, España

Yengny Marisol Silva Laya Universidad Iberoamericana, México

Aida Terrón Bañuelos Universidad de Oviedo, España

Jurjo Torres Santomé Universidad de la Coruña, España

Antoni Verger Planells University of Amsterdam, Holanda

Mario Yapu Universidad Para la Investigación Estratégica, Bolivia 